\title{
Las grandes áreas metropolitanas en España: del crecimiento y la expansión residencial al estancamiento poblacional*
}

\author{
Jordi Bayona-i-Carrasco \\ Centre d'Estudis Demogràfics - CERCA \\ Universitat de Barcelona. Departament de Geografia \\ jbayona@ced.uab.es
}

\section{Isabel Pujadas Rúbies}

Universitat de Barcelona. Departament de Geografia

ipujadas@ub.edu

Recibido: noviembre de 2018

Aceptado: mayo de 2019

Publicado: julio de 2019

\section{Resumen}

Durante los primeros años de siglo xxi la aceleración migratoria y la crisis económica posterior marcaron dos hitos importantes en el desarrollo poblacional de las principales áreas metropolitanas de España. En un primer momento, estas volvieron a ganar volúmenes importantes de población, con lo que se revirtieron las pérdidas demográficas de los centros metropolitanos y se consolidaron y se expandieron las periferias. Más tarde se produjo una caída brusca de estas dinámicas, lo que dio lugar a una fase de estancamiento demográfico y a la posible finalización de las tendencias dominantes de suburbanización. Actualmente, una estructura demográfica envejecida acompañada de la alternancia de generaciones muy nutridas en edades adultas y jóvenes en el pasado reciente con generaciones de escasos efectivos, así como la baja fecundidad imperante, hacen pensar en un menor potencial de crecimiento. Se trata de un cambio de paradigma donde las diferencias socioterritoriales entre centro y periferias se irán reduciendo, dada la menor intensidad de los principales factores demográficos que actúan sobre las áreas estudiadas.

Palabras clave: regiones metropolitanas; dinámica demográfica; flujos migratorios; estructura por edades; España

* Este trabajo se ha realizado bajo el proyecto de I+D+I Nuevas movilidades y reconfiguración sociorresidencial en la poscrisis: consecuencias socioeconómicas y demográficas en las áreas urbanas españolas (RTI2018-095667-B-I00), dirigido por la Dra. Cristina López Villanueva y el Dr. Fernando Gil, y financiado por la Agencia Estatal de Investigación y el Fondo Europeo de Desarrollo Regional (AEI/FEDER, UE), y el proyecto Desigualdad social, polarización territorial y formación de espacios vulnerables en las grandes áreas metropolitanas españolas (CSO2015-65219-C2- 1-R), dirigido por la Dra. Isabel Pujadas y el Dr. Fernando Gil, y financiado por el Ministerio de Economía y Competitividad (MINECO-FEDER). 
Resum. Les grans àrees metropolitanes a Espanya: del creixement $i$ l'expansió residencial a l'estancament poblacional

En els primers anys del segle xxi l'acceleració migratòria i la crisi econòmica posterior marquen dues fites importants en el desenvolupament poblacional de les principals àrees metropolitanes espanyoles. Al començament, aquestes van tornar a guanyar volums importants de població, amb la qual cosa es van revertir les pèrdues demogràfiques dels centres metropolitans i es va consolidar i expandir la periferia, més tard es va produir una caiguda brusca d'aquestes dinàmiques que va donar pas a una fase d'estancament demogràfic $\mathrm{i}$ a la possible finalització de la dinàmica imperant de suburbanització. Actualment, tant una estructura demogràfica envellida com la baixa fecunditat imperant fan pensar en un potencial més baix de creixement. Es tracta d'un canvi de paradigma on les diferències socioterritorials entre centre i periferia s'aniran reduint, atesa la intensitat més baixa dels fenòmens demogràfics principals que actuen sobre les àrees estudiades.

Paraules clau: regions metropolitanes; dinàmica demogràfica; fluxos migratoris; estructura per edats; Espanya

Resumé. Les grandes régions métropolitaines en Espagne : de la croissance et de l'expansion résidentielle à la stagnation de la population

Au cours des premières années du xxie siècle, l'accélération de la migration et la crise économique qui a suivi ont marqué deux jalons importants dans le développement de la population des principales régions métropolitaines d'Espagne. Premièrement, celles-ci ont regagné d'importants volumes de population, en inversant les pertes démographiques des centres métropolitains tout en consolidant et en élargissant la périphérie ; plus tard, il y a une chute soudaine de ces dynamiques, donnant lieu à une situation de stagnation démographique et à la fin possible de la dynamique de banlieusardisation qui prévalait. Actuellement, une structure démographique vieillissante ainsi qu'une faible fécondité dominante suggèrent un potentiel de croissance plus faible. Nous sommes confrontés à un changement de paradigme où les différences socioterritoriales sont réduites, étant donné l'intensité moindre des principaux facteurs démographiques agissant sur les zones étudiées.

Mots-clés: régions métropolitaines; dynamique démographique; flux migratoires; structure par âge; Espagne

Abstract. Large metropolitan areas in Spain: From growth and residential expansion to population stagnation

In the first years of the 21st century, the acceleration of migration flows and the subsequent economic crisis marked two important milestones in the population development of the main metropolitan areas of Spain. Initially, population growth was high, thus reversing the demographic decline of the main metropolitan areas and consolidating and expanding the periphery. Later, there was a sudden fall in these dynamics, giving rise to a phase of demographic stagnation that brought the then prevailing trend toward suburbanization to an end. Currently, both the aging demographic structure and low fertility suggest a lower potential for growth. These factors constitute a paradigm shift in which socio-territorial differences are reduced due to the lower intensity of the main demographic factors acting on the areas studied.

Keywords: metropolitan areas; demographic dynamics; migratory flows; age structure; Spain 


\section{Sumario}
1. Introducción
5. De la «década prodigiosa» al
2. Fuentes estadísticas y aspectos estancamiento demográfico: 2001-2016
metodológicos
3. El crecimiento urbano en España.
6. Los flujos migratorios internos metropolitanos
Un recorrido secular
7. La composición de la población por edades
4. Las dinámicas de crecimiento

8. Conclusiones

de los centros urbanos y las periferias

Referencias bibliográficas

\section{Introducción}

En los años más recientes, las principales regiones metropolitanas de España se han encontrado inmersas en una nueva etapa de su desarrollo urbano y poblacional. Esta etapa se está caracterizando por el estancamiento demográfico, consecuencia directa de la incidencia de la crisis económica sobre las dinámicas migratorias y poblacionales de sus habitantes, pero también de las repercusiones de una persistente débil fecundidad, que ha modificado las estructuras a favor de un crecimiento natural muy reducido o incluso negativo. Este último periodo también se caracteriza por la reducción del éxodo urbano, con claros indicios de estar finalizando la dinámica de fuerte intensidad conocida durante los últimos decenios (Bayona et al., 2018; López-Gay, 2017), que tuvo un elevado impacto territorial en la Región Metropolitana de Barcelona (Módenes, 1998; García-López, 2008; Pujadas, 2009; Nel.lo, 2010; Miralles, 2011; Bayona y Pujadas, 2014; García Coll y López Villanueva, 2017), pero también en la de Madrid (García Palomares y Gutiérrez Puebla, 2007; Bayona y Pujadas, 2014; Pozo y Rodríguez Moya, 2018) y en las principales regiones metropolitanas españolas (Susino y Duque, 2013; Salom y Albertos, 2014), y que afectó incluso a las ciudades intermedias del país (Ganau y Vilagrasa, 2003), en un proceso que difícilmente volverá a producirse con la misma intensidad que la conocida durante estas últimas décadas en España.

Los cambios que se observan en la actualidad se producen, además, después de una década, la de inicios de siglo XxI, donde se experimentó un intenso crecimiento demográfico en España, el mayor en perspectiva histórica, tanto en términos absolutos como relativos. Las grandes regiones metropolitanas también fueron partícipes de ello, ya que recuperaron altas intensidades de crecimiento demográfico que eran desconocidas desde la década de 1970. A continuación, la disminución de los flujos migratorios internacionales en España en relación con la crisis económica (Domingo y Blanes, 2015) ha actuado como uno de los principales desencadenantes del cambio hacia la situación actual.

El crecimiento demográfico de las regiones metropolitanas ha sido ampliamente estudiado, lo que ha dado lugar a diferentes modelos interpretativos que reproducen las diversas y sucesivas etapas en que la literatura internacional 
ha subdividido la evolución urbana (Champion, 2001; Van den Berg et al., 1982). Estas aproximaciones teóricas han sido reconceptualizadas por Rérat (2012), al incluir en esta periodización los vaivenes de la inmigración internacional, principal componente del crecimiento moderno de la población. Hoy en día, en un contexto de dinámicas naturales de crecimiento reducido o incluso negativo, los procesos de crecimiento de los centros metropolitanos y de sus periferias dependen directamente de la aportación poblacional de la migración internacional.

En el análisis de las etapas de desarrollo metropolitano en España desde un punto de vista de su crecimiento poblacional, Nel.lo (2004 y 2007) indica que las grandes metrópolis seguirían los patrones clásicos europeos de este desarrollo urbano, que se encontraban a inicios de siglo XXI en una fase de «recentralización». Coincidiendo con el análisis de Rérat (2012) para las ciudades suizas, y a diferencia del marco teórico clásico, dicho fenómeno no se debería al retorno de la población al centro urbano, sino a la entrada de amplios volúmenes de inmigrantes foráneos. Con ello se inició una nueva fase de desarrollo urbano (Feria, 2010; Pujadas et al., 2013), donde continuaban los procesos de suburbanización retroalimentados por la llegada al centro de inmigrantes extranjeros (Bayona y Gil, 2012; Pozo y García Palomares, 2009). Estos inmigrantes, al mismo tiempo, se han añadido progresivamente a dichas dinámicas de redistribución desde la ciudad central, potenciándolas e incidiendo en el crecimiento de las áreas más vulnerables de las metrópolis españolas, donde se han asentado principalmente. Esta última etapa se daría por finalizada (Pujadas y Bayona, 2017), en cuanto los principales actores de la misma, los flujos migratorios internacionales y la suburbanización residencial decaerían por la crisis económica e inmobiliaria (Pozo y Rodríguez Moya, 2018, para el caso de Madrid). Las áreas de Barcelona y Madrid muestran situaciones siempre más maduras, y avanzan comportamientos que después se observan en el resto de ciudades (De Cos, 2007).

En este contexto, el principal objetivo del presente artículo es sintetizar el alcance y la intensidad de estas dinámicas recientes, centrando la atención en las transformaciones que se producen en las cinco mayores regiones metropolitanas españolas (Madrid, Barcelona, Valencia, Sevilla y Bilbao, por orden según sus volúmenes de población). Para ello, en primer lugar, se analizará la evolución histórica de la población, de 1900 a 2016, de los municipios españoles, urbanos y rurales, así como la de las principales regiones urbanas. En segundo lugar, se tratará la evolución de las cinco regiones metropolitanas comparando la intensidad del crecimiento de la ciudad central y de su periferia en una perspectiva temporal de largo plazo, de 1900 a 2016. En tercer lugar, se presentará desde una perspectiva comparativa la evolución de los cuatro fenómenos que, a nuestro entender, mayor influencia ejercen actualmente sobre el desarrollo metropolitano desde una perspectiva demográfica:

1. La evolución de los flujos migratorios internos entre el centro y las periferias metropolitanas. 
2. El impacto de la inmigración extranjera.

3. La existencia de estructuras demográficas diferenciales y sus modificaciones en el tiempo.

4. La evolución de la dinámica demográfica natural.

En comparación con contribuciones precedentes, en esta ocasión la atención se volcará en el tercer punto, las estructuras demográficas, en las que repercuten los cambios demográficos y territoriales analizados.

\section{Fuentes estadísticas y aspectos metodológicos}

Para el presente trabajo se han utilizado las series de población municipales elaboradas desde la Fundación BBVA y el Instituto Valenciano de Investigaciones Económicas (IVIE), que reconstruyen, desde inicios de siglo xx, los municipios españoles y su población. Esta serie se ha actualizado para los años más recientes añadiendo los datos del Padrón continuo de población de enero de 2016, con los que se han analizado las poblaciones por sexo y edad de los centros y las periferias metropolitanas. Con estos datos se han calculado las tasas de crecimiento anual acumulativas $(r)$ para los distintos municipios y áreas metropolitanas, empleando la siguiente formulación:

$$
r=\left(\sqrt[t]{\frac{P_{t}}{P_{0}}}-1\right) \times 100
$$

donde $\mathrm{P}_{0}$ es la población inicial; $\mathrm{P}_{\mathrm{t}}$, la población final, $\mathrm{y} t$, el número de años del periodo considerado.

Desde una perspectiva territorial, se han analizado las cinco mayores regiones metropolitanas de España: Madrid, Barcelona, Sevilla, Valencia y Bilbao. Debido a la falta de una delimitación administrativa comúnmente aceptada de las regiones metropolitanas en España, se ha empleado la definición de las mismas que se obtiene a partir del proyecto europeo Urban Audit. Por ello se han utilizado las áreas funcionales de Eurostat (AUF) establecidas para el año 2013, lo que al mismo tiempo garantiza la comparabilidad internacional. Según dicha delimitación, las cinco regiones analizadas engloban conjuntamente 407 municipios que ocupan $15.196 \mathrm{~km}^{2}$ y suman 15,5 millones de habitantes en el año 2016, lo que significa alrededor de una tercera parte de los residentes del país ${ }^{1}$.

1. Madrid es la de mayor tamaño, con 137 municipios que ocupan $6.827 \mathrm{~km}^{2}$ y una población de 6.545.284 habitantes en 2016; Sevilla, con $3.401 \mathrm{~km}^{2}$, está compuesta por 39 municipios y cuenta con 1.418.348 habitantes; para Barcelona se consideran 128 municipios que ocupan $2.437 \mathrm{~km}^{2}$ y una población de 4.910 .438 habitantes; en la región de Bilbao encontramos 54 municipios que ocupan $1.489 \mathrm{~km}^{2}$ y 1.020 .986 habitantes; finalmente, en el caso de Valencia, se contemplan 49 municipios que ocupan $1.042 \mathrm{~km}^{2}$ y una población de 1.625.152 habitantes. 
Para analizar el aumento de la población se ha calculado la tasa de crecimiento anual acumulativo ( $r$ ), primero para el conjunto de España y sus mayores áreas metropolitanas, entre 1900 y 2016 (figura 1), diferenciando entre centro y periferia (figura 3$)^{2}$, y para los municipios metropolitanos desde 1960 (figura 2). Se toma esta fecha como origen de dicho análisis por coincidir con la etapa de crecimiento urbano de mayor intensidad y con una fuerte polarización en la dinámica urbana en España. Con estos datos se ha construido un diagrama de caja o boxplot (figura 2), donde se representa la mediana con una línea de mayor grosor, y los extremos de la caja representan el primer y tercer cuartil, mientras que las líneas muestran los valores mínimos y máximos de crecimiento. Finalmente, y con datos decenales desde 1900, se diferencia el crecimiento entre centros y periferias metropolitanas (figura 3).

También se han analizado las migraciones internas metropolitanas empleando los microdatos de la Estadística de Variaciones Residenciales (EVR). Esta fuente recoge las altas y las bajas registradas en el Padrón continuo de población, indicando el municipio de origen y el de destino, así como las principales características demográficas de los migrantes (sexo, edad, nacionalidad y lugar de nacimiento). Somos conscientes de que la EVR arrastra los problemas de registro del Padrón continuo de población, pero se trata de la única fuente estadística con información municipal de las migraciones realizadas entre municipios en España, con la ventaja que proporciona datos anuales. En esta ocasión la atención se focaliza en los últimos doce años, los comprendidos entre 2005 y 2016, lo que nos permite distinguir tres periodos de igual duración y que corresponden a coyunturas claramente diferenciadas: 2005-2008, 20092012 y 2013-2016. El primero coincide con los últimos años de crecimiento económico y con el inicio de la crisis inmobiliaria, primero, y económica, más tarde, con un comportamiento similar a los años precedentes. El segundo recoge los momentos más duros de la crisis, tanto en su primer impacto sobre la construcción como en los recortes en el sector público de 2011 y 2012. El tercer periodo se localiza en momentos donde se empezaron a suavizar algunos de los efectos más graves de la crisis económica, especialmente en los últimos dos años de dicho periodo. Con estos mismos años, 2005, 2009, 2013 y 2016, se presenta en la figura 5 la evolución de la proporción de inmigrantes en los centros y en las periferias metropolitanas.

A continuación, con el Padrón continuo de población de 2016, última fecha disponible en el momento de realizar este trabajo, se analiza la estructura por edades de los centros y las periferias metropolitanas, comparando los resultados con los obtenidos con el análisis de 1998 (primer año disponible) y 2005 (que coincide con el primer año de análisis de los flujos migratorios internos), en ambas fechas utilizando también el Padrón continuo de población, para dar cuenta de la evolución reciente y de la estructura demográfica actual. Para

2. En el caso de Barcelona, por ejemplo, los orígenes de la dispersión metropolitana tienen que buscarse en esos años, cuando, entre 1900 y 1940, la ciudad central duplica su población, pero también lo hace su periferia. 
Figura 1. Evolución demográfica (tasas de crecimiento anual acumulativo en tanto por ciento) de los municipios metropolitanos y el resto de municipios (España, 1900-2016)

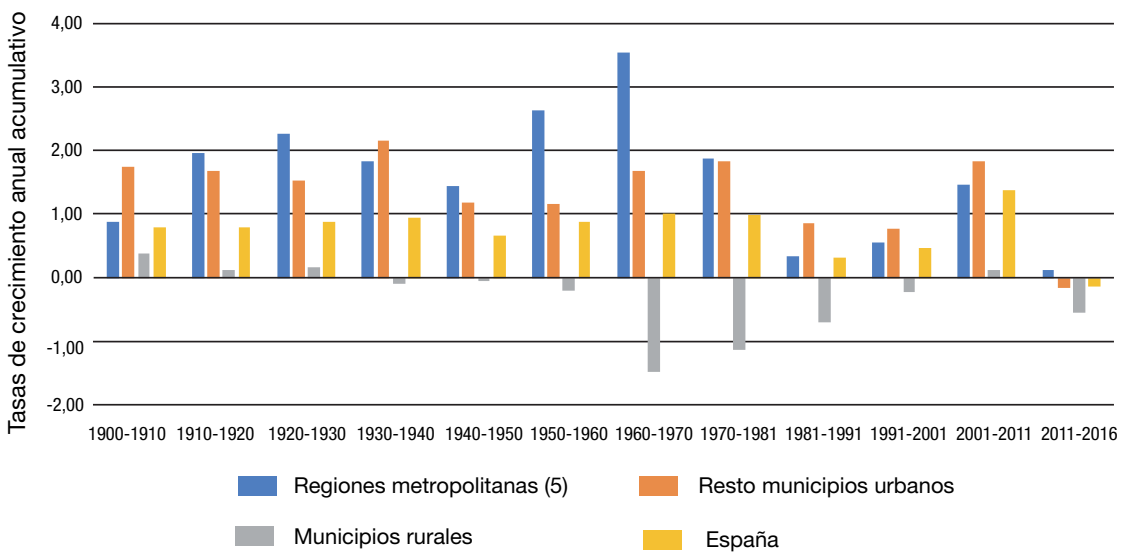

Fuente: Fundación BBVA e IVIE, Cambios en la estructura y la localización de la población: Series homogéneas (1900-2011) (<http://www.fbbva.es/TLFU/tlfu/esp/areas/econosoc/bbdd/serieshomg.jsp>), y Padrón continuo de población, con datos del INE. Elaboración propia.

concluir y aportar algunas cifras de la dinámica natural se emplean los datos del Movimiento Natural de la Población (MNP), referidos a los nacimientos y a las defunciones a escala municipal del trienio 2013-2015, que ayudan a situar la evolución más reciente de la dinámica demográfica metropolitana.

\section{El crecimiento urbano en España. Un recorrido secular}

Antes de analizar las dinámicas metropolitanas recientes se presenta un breve recorrido histórico que permite contextualizar la situación actual. La población española experimentó un intenso aumento durante el siglo xx, desde los 18,6 millones de 1900 hasta los 40,8 millones de 2001. Junto al crecimiento, es importante señalar los cambios ocurridos en la distribución de la población, ya que hubo un potente proceso de concentración urbana que desplazó la población hacia las zonas de costa y las principales regiones metropolitanas del país (Goerlich y Mas, 2008; Reques, 2017). En los años veinte y treinta se consolidó este proceso (Franch et al., 2013; García Docampo y Otero, 2012; Reques, 2017), que se apuntaló en los años cincuenta y sesenta con la despoblación de amplias zonas rurales del país (De Cos y Reques, 2005; García Coll y Pujadas, 1997). Buena parte de este crecimiento se produjo en las cinco regiones metropolitanas analizadas en este trabajo. En ellas el crecimiento demográfico conllevó multiplicar por 6,5 su número de residentes, desde los 2,4 millones hasta los 15,5 millones de la actualidad. El aumento fue más potente entre 1910 y 1981 (ver figura 1), y alcanzó sus picos de mayor intensidad en la década de 1960, cuando en apenas diez años se pasó de 7,1 a 10,1 millones 
de residentes y se conocieron crecimientos relativos superiores al 3,5\% anual. Son los mismos años en que los municipios rurales de España (considerando los menores a 10 mil habitantes en cada recuento censal) conocieron tasas negativas de crecimiento de elevada intensidad.

A diferencia de lo que sucede en las cinco grandes regiones metropolitanas, es en la primera década del siglo xxI cuando se observa el mayor aumento demográfico de España. En este periodo incluso los municipios rurales recuperan población, lo que no se producía desde la década de 1920. Para las cinco regiones metropolitanas que centran nuestro análisis, el periodo 2001-2011 significa el retorno a intensidades de crecimiento abandonadas en los años setenta. El periodo más reciente, en cambio, con datos entre 2011 y 2016, registra por primera vez un decrecimiento de la población española, del cual aún se libran las cinco áreas analizadas, a pesar de conocer el crecimiento relativo más bajo de la serie histórica analizada. Generalizando, y vista esta evolución, desde mediados de siglo Xx, en las áreas metropolitanas españolas se pueden distinguir hasta cinco grandes etapas (Alabart, 2007; López-Villanueva y Pujadas, 2015):

1. Una etapa de urbanización de alta densidad, que se produce entre los años 1950 y 1975 y que se caracteriza por la fuerte polarización de las dinámicas demográficas en España, produciéndose un intenso crecimiento urbano al mismo tiempo que este coincide con el máximo despoblamiento rural (ver las figuras 1 y 2 ).

2. El inicio de la descentralización, en la década comprendida entre 1975 y 1986, con una importante inflexión en comparación con la dinámica precedente (Nel.lo, 2004). Coincide con la crisis económica, y durante esta etapa se produce una importante reducción de las migraciones del campo a la ciudad y también un descenso rápido y generalizado de la natalidad. Se caracteriza por un crecimiento demográfico muy reducido.

3. Una etapa de descentralización y de suburbanización de baja densidad, que empezaría en los años ochenta y finalizaría entre 1996 y 2001, dependiendo de la ciudad. Se produciría un crecimiento de las nuevas periferias residenciales de baja densidad, al mismo tiempo que se observan importantes cambios en los comportamientos sociodemográficos de la población, conductas que se relacionan con los estadios iniciales de lo que se ha venido a llamar «segunda transición demográfica» (ver López Villanueva y Pujadas, 2005, para el análisis de sus efectos en la RMB).

4. La etapa de reurbanización y crecimiento de la ciudad central gracias a la llegada de la inmigración internacional y de su asentamiento en las áreas centrales (1996-2008), más su posterior diseminación por el resto de la metrópolis.

5. Finalmente, una última etapa de crisis y estancamiento (2009-2016), donde se produce un crecimiento muy escaso e incluso negativo para algunos municipios. Al mismo tiempo, se observa una reducción de los flujos migratorios, tanto de los internacionales como de los que se producen a escala intrametropolitana, lo que atenúa el éxodo urbano característico de las etapas precedentes. 
A pesar de las oscilaciones experimentadas, durante todo el siglo xx y los quince primeros años del XxI, las grandes regiones metropolitanas analizadas han mantenido sistemáticamente un crecimiento demográfico superior al observado en el conjunto de España. Durante las décadas de 1920, primero, y 1950 y 1960, más adelante, es cuando se experimentan los mayores incrementos demográficos. En las décadas más recientes se observa que los tres decenios comprendidos entre 1981 y 2011 muestran crecimientos muy similares entre las cinco áreas analizadas y el resto del país. En cierta medida, se acaba con el proceso de concentración territorial a favor de la dispersión residencial, y las diferencias en el crecimiento se manifiestan a escala metropolitana. En cambio, en el último quinquenio se observa que las cinco grandes regiones metropolitanas resisten demográficamente el descenso de población que se produce en el resto de España.

\section{Las dinámicas de crecimiento de los centros urbanos y las periferias}

En cuanto a la distribución interna de este crecimiento (figura 3), las metrópolis de Barcelona y Madrid muestran un comportamiento paralelo a partir de mediados del siglo xx. Anteriormente, el proceso de urbanización, de concentración urbana en el centro que se visibiliza en Madrid, no ocurre de igual forma en Barcelona, donde centro y periferia crecen al mismo ritmo, especialmente en la década de 1920, cuando se reciben intensos flujos migratorios que se asientan en la ciudad central y en su periferia inmediata (Arango, 2007). En cambio, y a partir de los años sesenta, en ambas regiones metropolitanas el crecimiento es mucho más destacado en las periferias, situación que coincide entre la década de 1980 e inicios de siglo xxI, con un decrecimiento poblacional de los centros metropolitanos. En el caso de Valencia, aunque a menor escala, se reproducen pautas metropolitanas similares, pero, al igual que sucede en Bilbao, las diferencias entre centro y periferia se difuminan y son de menor envergadura. En Sevilla, en cambio, las oscilaciones cíclicas son de menor entidad, observándose aumentos demográficos más lentos. En este caso centro y periferia se diferencian a partir de los años ochenta, situación que se debe al menor crecimiento de la ciudad central, ya que las periferias siguen creciendo a un ritmo bastante constante desde mediados de siglo.

En cuanto a los últimos años analizados, que finalizan en 2016 y que por tanto no alcanzan a comprender un decenio (con lo que la visión general de la década puede aún sufrir cambios importantes), estos inciden para las cinco metrópolis en igualar el crecimiento demográfico entre centros y periferias, lo que por sí mismo ya es una novedad. Esta situación estaría causada por profundos cambios en el proceso de suburbanización, no tanto en la reducción de la intensidad de las migraciones residenciales, que a pesar de producirse es moderada, sino en los orígenes y destinos de los mismos, que se difuminan (Bayona et al., 2018; Pujadas y Bayona, 2017; Gil-Alonso et al., 2016). Además, estas dinámicas poblacionales observadas responden a una estructura demográfica donde el peso de los adultos jóvenes es cada vez más baja. Al tratarse de grupos 
Figura 2. Boxplot de la evolución del crecimiento de los municipios metropolitanos (19602016), tasas de crecimiento anual acumulativo (\%)
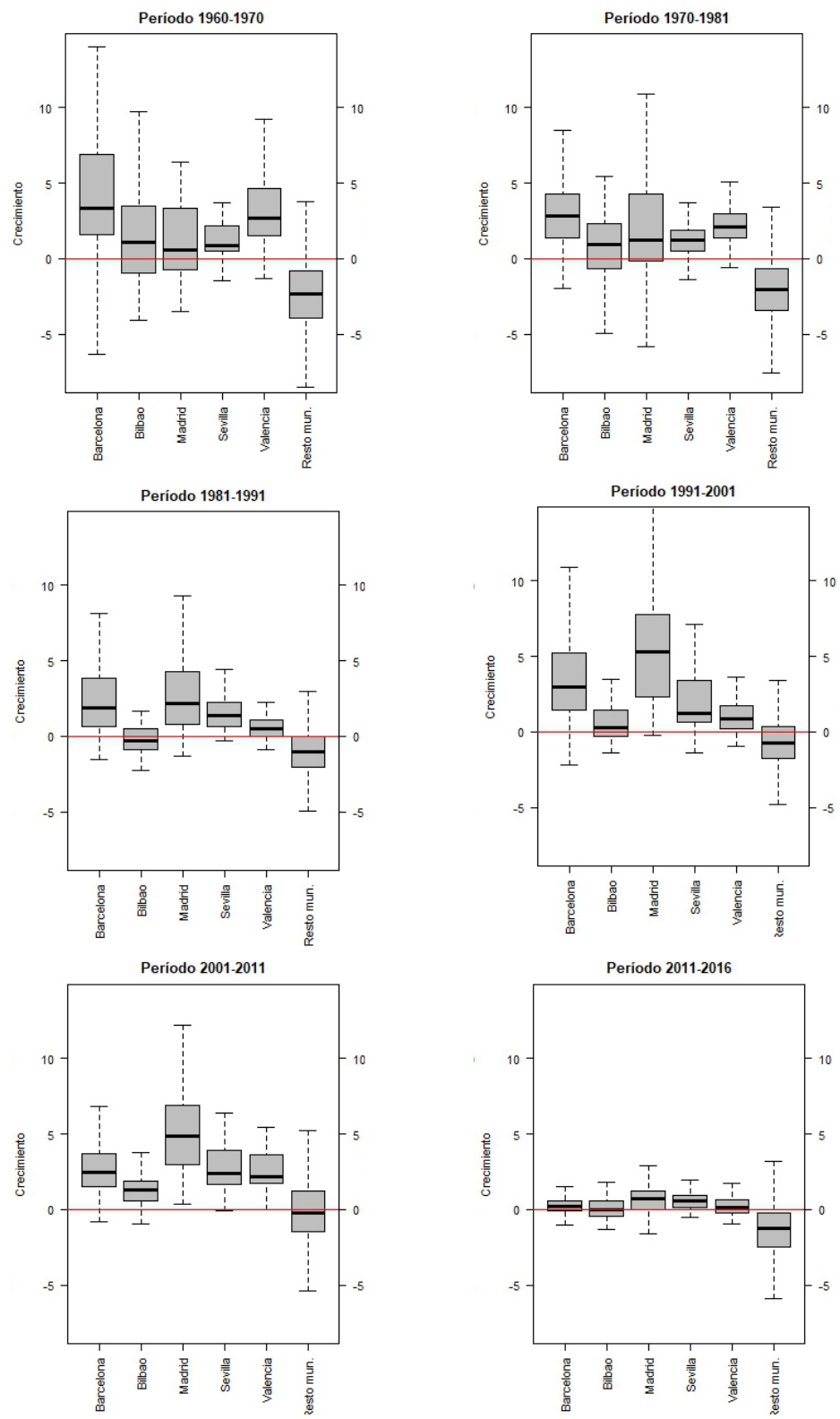

Fuente: Fundación BBVA e IVIE, Cambios en la estructura y localización de la población: Series homogéneas (1900-2011) (<http://www.fbbva.es/TLFU/tlfu/esp/areas/econosoc/bbdd/serieshomg.jsp>), y Padrón continuo de población, con datos del INE. Elaboración propia. 
Figura 3. Evolución de las tasas de crecimiento de la población en las regiones metropolitanas, centro y periferia (1900-2016)
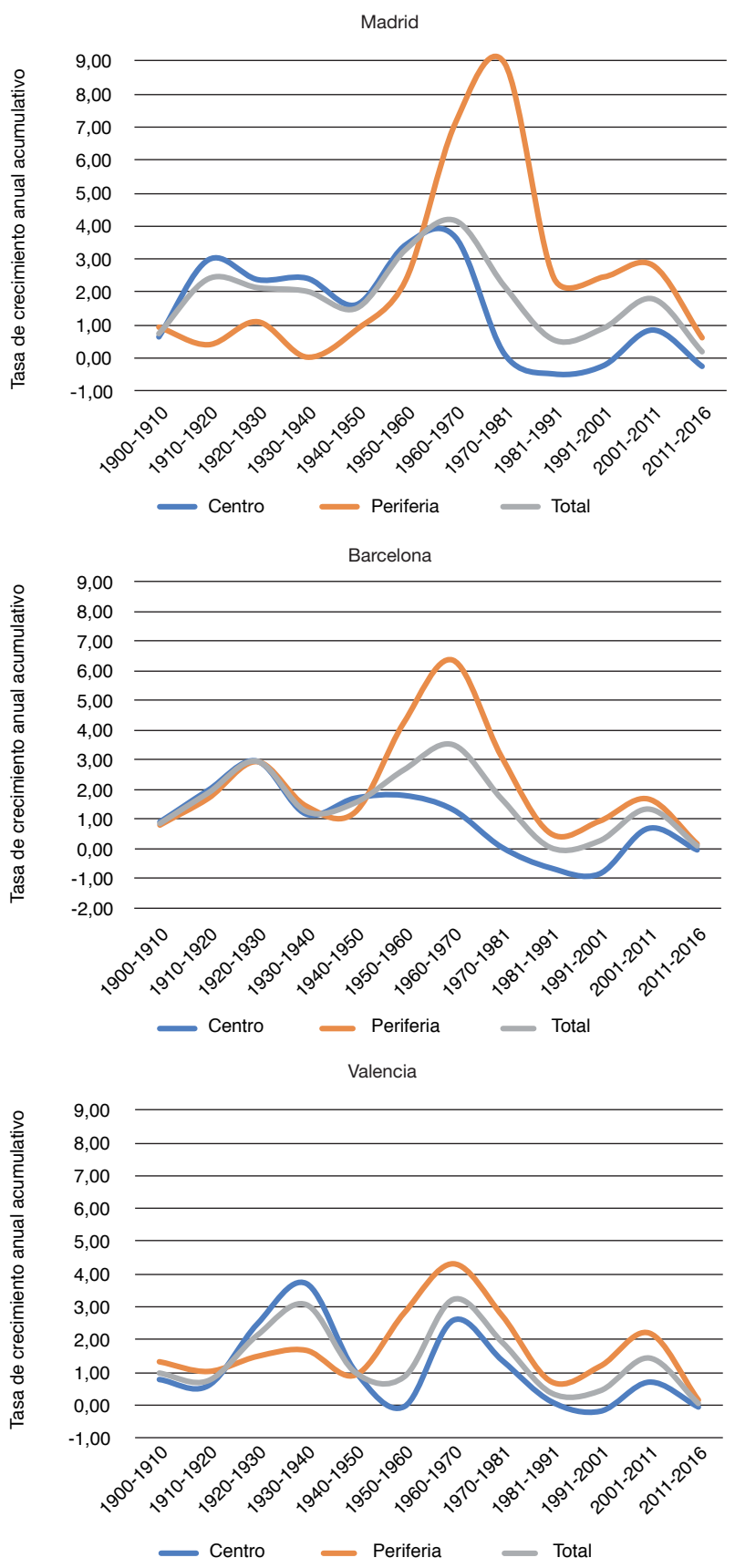


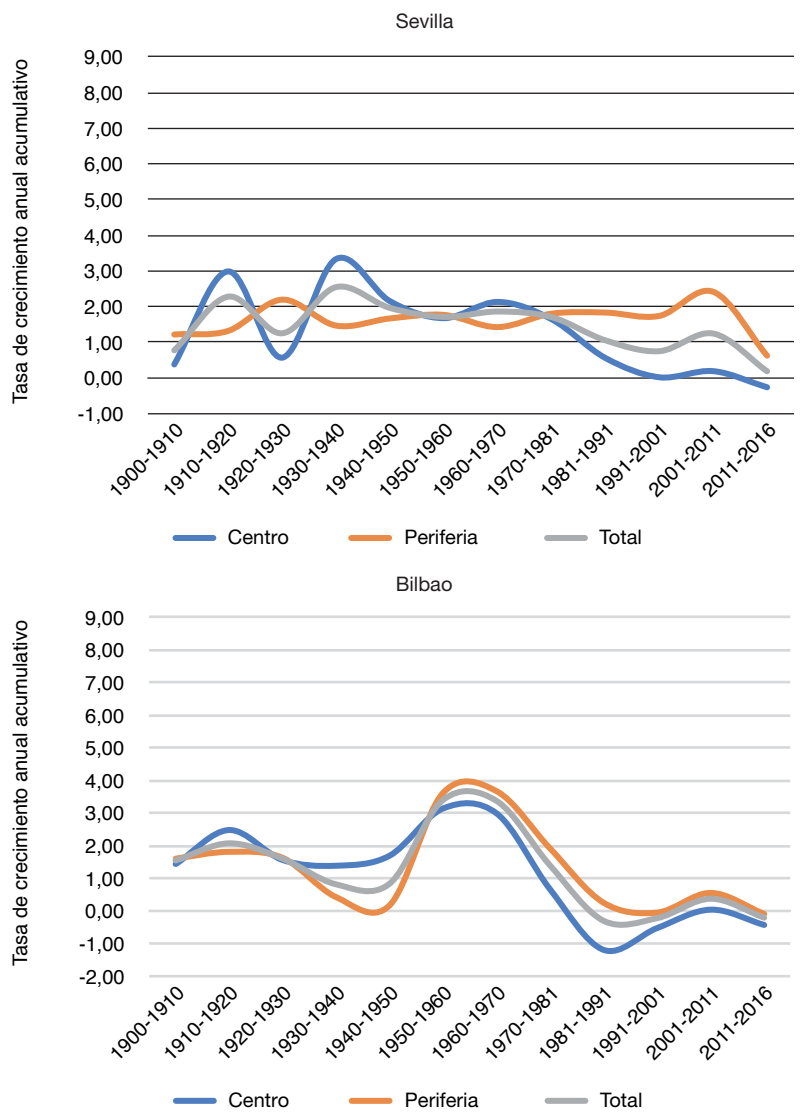

Fuente: Fundación BBVA e IVIE, Cambios en la estructura y localización de la población: Series homogéneas (1900-2011) (<http://www.fbbva.es/TLFU/tlfu/esp/areas/econosoc/bbdd/serieshomg.jsp>), y Padrón continuo de población, con datos del INE. Elaboración propia.

caracterizados por una mayor movilidad en relación con la formación de nuevos hogares, su menor representación en el conjunto de la población puede justificar, en parte, esta nueva situación. La mayor inestabilidad residencial observada en los últimos años (Módenes, 2019), que se traduce en crecimientos constantes del alquiler en el acceso a la vivienda, podría actuar en sentido opuesto haciendo crecer la intensidad, y justificaría el hecho de que en momentos de crisis económica no descendiera la intensidad de la movilidad residencial. Incluso explicaría el distinto comportamiento de los cambios de residencia internos en las grandes ciudades, que experimentan recorridos distintos a la movilidad residencial y donde el efecto del alquiler es más importante (Bayona y Recaño, 2016). En contraposición, el análisis de las tasas a escala metropolitana (Pujadas y Bayona, 2017; Bayona et al., 2018) muestra cómo esta situación no parece afectar a la distribución territorial de las migraciones a dicha escala. 


\section{De la «década prodigiosa» al estancamiento demográfico: 2001-2016}

A continuación fijamos la atención en lo sucedido durante los últimos quince años a escala municipal en las cinco áreas metropolitanas analizadas, que es la etapa que coincide con el decenio de mayor crecimiento demográfico y con los efectos de la crisis económica. Así, el crecimiento generalizado y con diferencias evidentes entre centros y periferias observado en la primera década da lugar a un estancamiento posterior, con práctica eliminación de dichas diferencias entre municipios. En los primeros años del siglo XXI, que Burriel (2008) califica como "década prodigiosa» del urbanismo español, las zonas de elevado crecimiento incluso desbordan los límites metropolitanos (Pozo y García-Palomares, 2009, por ejemplo, para Madrid), con aumentos importantes en áreas periféricas debido a varios factores, entre los que destacan los elevados precios inmobiliarios que se produjeron durante los años del boom inmobiliario y la llegada a la edad de emancipación de las generaciones nacidas en el baby boom español, además de la incorporación de un elevado número de inmigrantes extranjeros en la mayoría de estas zonas. A partir de la crisis económica, existe un descenso generalizado de las intensidades de crecimiento y una desaparición de dichas pautas (figura 4). A escala metropolitana, los crecimientos negativos, que fueron excepcionales en la primera década, se convierten en la norma, en un contexto general de estancamiento y con tasas próximas o por debajo de cero.

Por otro lado, las ciudades centrales observan un cambio de signo en su crecimiento poblacional. Aunque en la primera década del siglo Xxi dicho crecimiento fue recuperado después de años de descenso (figura 3), en los últimos tiempos este ha vuelto a mostrar tasas negativas de nuevo, bien que por ahora con bajas intensidades. Para estas ciudades, la primera década de este siglo ha representado un paréntesis en las dinámicas regresivas que caracterizaron los últimos decenios del siglo Xx.

En esta evolución la inmigración internacional ha desempeñado un papel muy importante, ya que es debido a su entrada e incorporación en las áreas centrales metropolitanas que las ciudades recuperan habitantes. Al mismo tiempo, el asentamiento de la población inmigrada provoca un crecimiento de las migraciones internas, a las que los inmigrados extranjeros se incorporan paulatinamente, con lo que muestran pautas territoriales complementarias a las de los autóctonos. Los datos presentados en la figura 5 revelan la importancia que adquiere la población inmigrada, que en Madrid y Barcelona supera el 20\% del número de habitantes del centro metropolitano y llega a valores de alrededor del 15\% en sus zonas periféricas. Esta proporción de inmigrantes es muy superior en las regiones metropolitanas de Barcelona y Madrid, principales focos urbanos de atracción en España, situación que se reproduce en menor medida en Valencia, mientras que en Sevilla y Bilbao las intensidades son bastante inferiores.

La crisis económica afecta de forma desigual a estos flujos. En algunos casos, incluso, el crecimiento continuado del stock de inmigrados internacionales de las ciudades centrales no se detiene con la crisis, como sucede en Bilbao o 
Figura 4. Tasas de crecimiento poblacional por municipio (2001-2011 y 2011-2016)
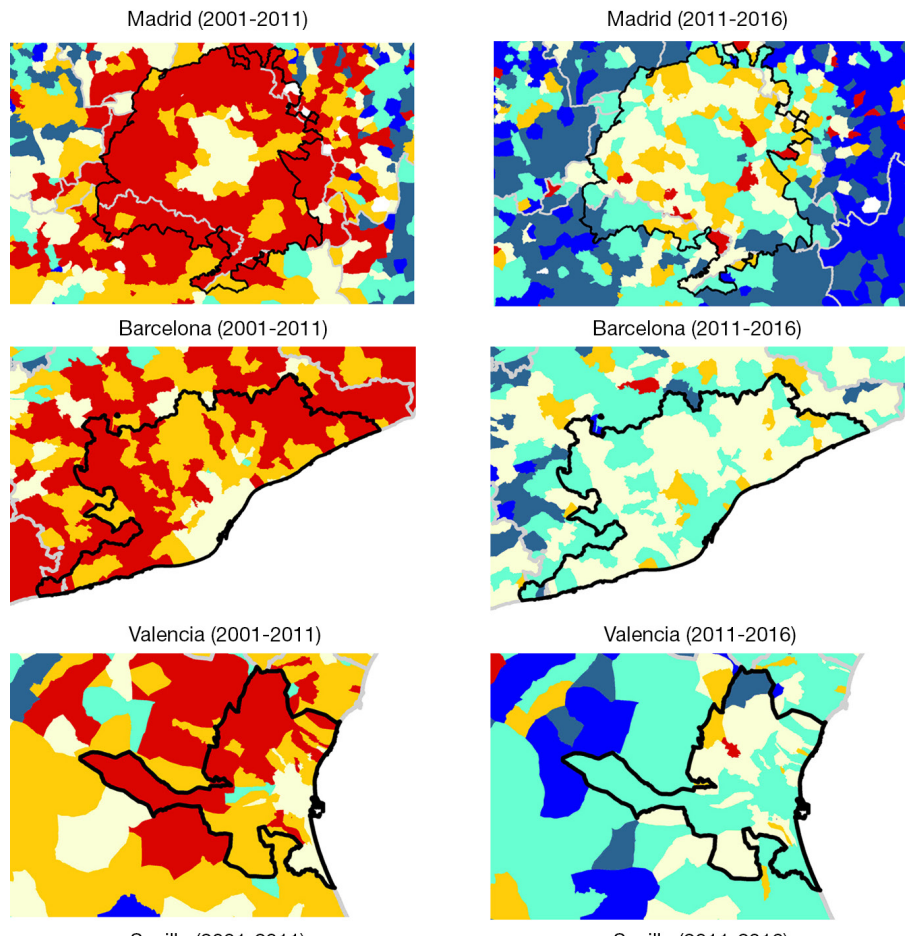

Sevilla (2001-2011)

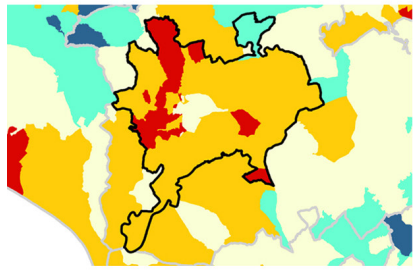

Sevilla (2011-2016)

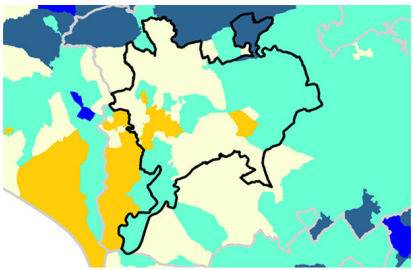

Bilbao (2001-2011)
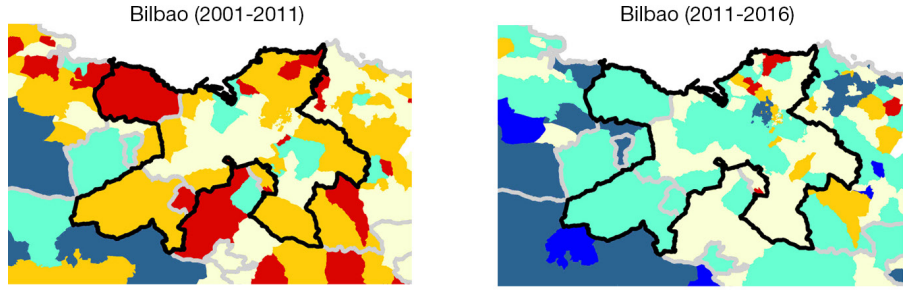

Por debajo del $-2,5 \%$

Entre el $-2,5 \%$ y el $-1,0 \%$

Entre el $-1,0 \%$ y el $0,0 \%$

Entre el $1,0 \%$ y el $2,5 \%$

Entre el $0,0 \%$ y el $1,0 \%$

Más del $2,5 \%$

Fuente: Fundación BBVA e IVIE. Cambios en la estructura y localización de la población: series homogéneas (1900-2011) (<http://www.fbbva.es/TLFU/tlfu/esp/areas/econosoc/bbdd/serieshomg.jsp>) y del Padrón continuo de población, con datos del INE. Elaboración propia. 
Figura 5. Evolución de la inmigración extranjera (2005-2016)

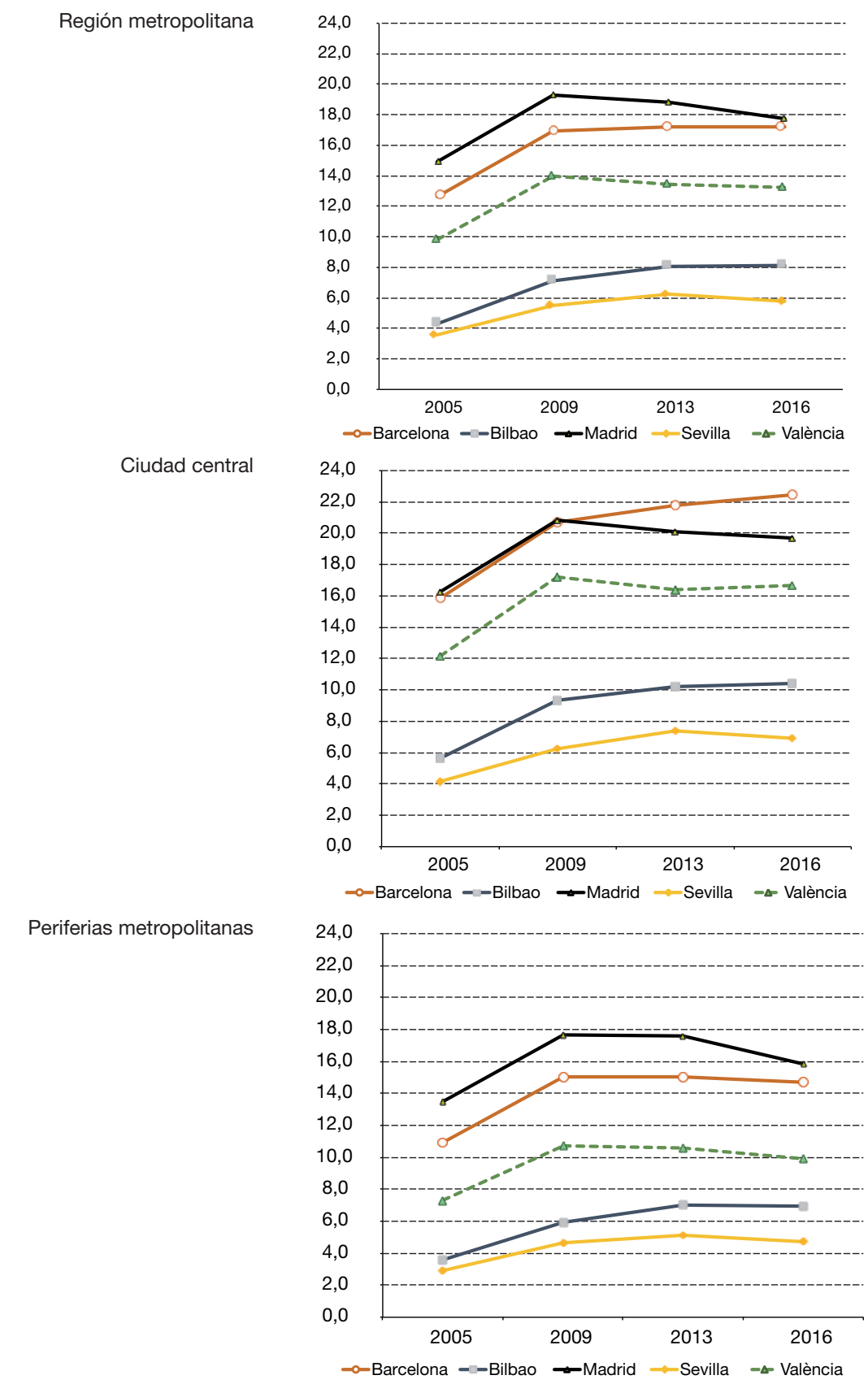

Fuente: elaboración propia. Datos del Padrón continuo de población, 2005-2016, INE. 
Figura 6. Dinámica demográfica reciente en las mayores regiones metropolitanas españolas (2013-2015)

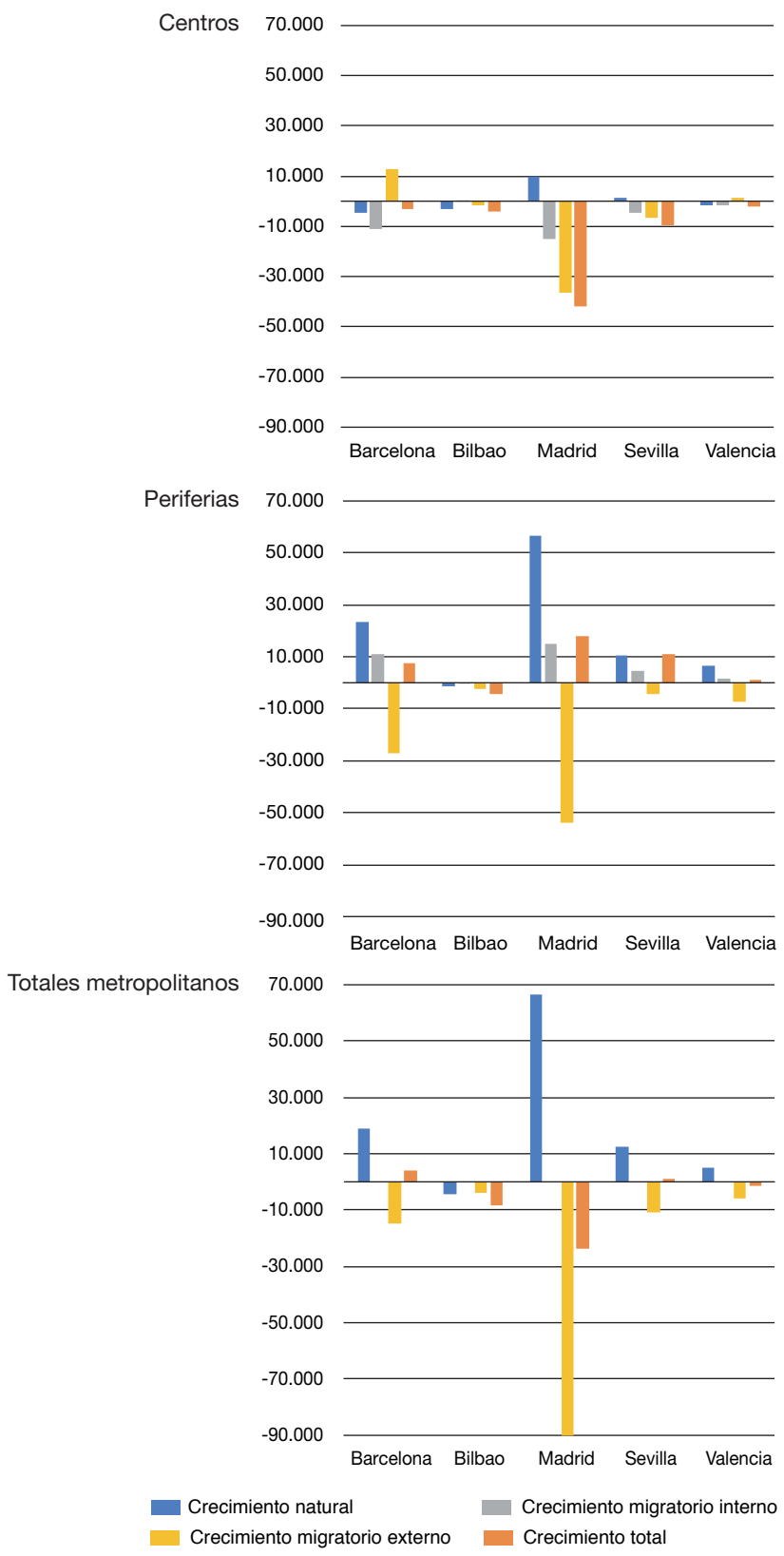

Nota: en el eje vertical se representan los valores absolutos.

Fuente: Movimiento natural de la población, 2013-2015, con datos del INE. 
Barcelona, mientras que en Valencia y Madrid se observa un leve descenso, al igual que en Sevilla después de 2013. En cambio, en las periferias es más difícil observar este crecimiento, que solo se produce en Bilbao. En estas grandes áreas metropolitanas, los efectos de la crisis sobre los efectivos de inmigrados han sido menores que en el resto de España, manteniendo, a grandes rasgos, las mismas cifras que en 2009.

Finalmente, y para los años más recientes (el trienio 2013-2015), se muestra la relación entre crecimiento de la población, dinámica demográfica y migraciones internas y externas a las metrópolis estudiadas (figura 6), coincidiendo con el periodo de menor impacto de la crisis económica. En estos tres años las regiones metropolitanas de Madrid, Bilbao y Valencia pierden, por este orden, población total, mientras que en las dos restantes, Barcelona y Sevilla, el número de sus habitantes aumenta ligeramente. Desde la perspectiva territorial, los centros siguen perdiendo población, mientras que las periferias, a excepción de Bilbao, recuperan residentes. En cuanto al crecimiento natural, en las ciudades centrales este es negativo, a excepción de Sevilla y Madrid, donde se siguen registrando cifras positivas, aunque poco importantes por su baja intensidad. En cambio, en las periferias el saldo natural es generalmente positivo, a excepción de Bilbao. Como diferencia entre saldo natural y crecimiento total se ha calculado el saldo migratorio, distinguiendo entre saldo migratorio interno (el ya calculado anteriormente con las EVR) y saldo migratorio externo metropolitano (tanto con el resto del país como con el exterior). El resultado de esta operación sigue diciendo que la migración interna es, a excepción de Bilbao, negativa en el centro y positiva en la periferia, mientras que el crecimiento migratorio externo (mayoritariamente inmigración internacional) solo compensa en Barcelona y ligeramente en Valencia las pérdidas poblacionales de los centros. La diversidad de situaciones presentadas, junto con el papel aún importante de la dinámica natural en las periferias metropolitanas, son quizás las conclusiones más destacadas de este ejercicio.

\section{Los flujos migratorios internos metropolitanos}

La dinámica migratoria metropolitana es observada a través del análisis de las migraciones internas proporcionado por las EVR (ver figuras 7 y 8). En la primera figura, y para el periodo 2005-2016, se percibe que el saldo migratorio entre las ciudades centrales y sus periferias metropolitanas presenta una tendencia general hacia la reducción de las cifras negativas, dinámica que se reproduce con igual calendario en las cinco regiones metropolitanas. Las pérdidas por migración intrametropolitana en Madrid alcanzan cifras elevadas (de 20.000 a 30.000 migrantes anuales entre 2005 y 2009), con una rápida reducción en los años posteriores, pero manteniendo siempre su saldo negativo. En el área urbana funcional de Barcelona los saldos negativos anuales del centro metropolitano se sitúan entre los 10.000 y los 20.000 migrantes durante el periodo 2005-2008, con un descenso rápido en los años siguientes, siguiendo la misma tendencia que en Madrid. En los casos de Sevilla y Valencia las pérdidas por 
migración suburbana se dan también entre 2005 y 2008, con valores en torno a 5.000 y 10.000 migrantes. En cambio, en Bilbao el saldo migratorio es muy reducido en todo el periodo analizado, mostrando un escaso efecto de la movilidad residencial y siendo también el único caso en el que se produce una ligera recentralización, es decir, se alcanza un saldo migratorio interno positivo, aunque este es de muy baja intensidad.

Conviene, además, señalar que esta evolución se ve interrumpida de forma reciente, primero y desde 2014 en Madrid y Barcelona, lo que da lugar a un cambio de tendencia, con un nuevo aumento de los saldos negativos, que de forma incipiente también parecen repetir en los casos de las ciudades de Valencia y Bilbao. El crecimiento reciente de los precios inmobiliarios en las urbes centrales está relacionado tanto con la progresiva mejora económica como con los procesos de gentrificación y turistificación observados en las áreas centrales (Cocola, 2018; Donat, 2018), lo que podría explicar esta reciente inflexión. En esta evolución cabe señalar como la población de origen inmigrante ha experimentado un retorno a la ciudad central de mayor intensidad que el de la población autóctona, situación especialmente visible en el caso de Madrid, mientras que entre los autóctonos esta inversión del signo del saldo solo llega a producirse en Bilbao.

Para profundizar en el análisis de los protagonistas de este proceso, en la figura 8 se detalla el perfil de este saldo migratorio por edades. En este caso, y vista la evolución anterior, se divide el periodo de análisis en tres grandes etapas (2005-2008, 2009-2012 y 2013-2016). En ellas se observan permanencias y cambios que sugieren dinámicas contrapuestas en función de la edad y la generación. Por un lado, y como hecho más destacable, existe una fuerte reducción de la pérdida de efectivos en los años que se corresponden a edades de formación de un nuevo hogar, hasta ahora los verdaderos protagonistas de la suburbanización. Este descenso de la pérdida de jóvenes entre centro y periferia metropolitana se produce ininterrumpida y progresivamente en Madrid, Valencia y Sevilla (es decir, durante los tres periodos analizados), y se concentra en los dos primeros periodos en Barcelona y Bilbao.

Una situación similar se reproduce entre los menores de edad (debido a que son migraciones de arrastre de los primeros), lo cual respondía a la suburbanización de familias con hijos menores. Esta pérdida inferior de efectivos jóvenes se produce tanto por un descenso de la intensidad del proceso de suburbanización como por importantes cambios en la estructura demográfica, con un número de jóvenes más reducido en consonancia con la evolución histórica de la fecundidad ${ }^{3}$.

En segundo lugar, se registra una ligera pauta de recentralización en algunos grupos de edad. Es el caso de aquellas personas que se sitúan alrededor de los cincuenta años, situación especialmente visible en Madrid y que muestra un comportamiento temporal similar al caso anterior. Tam-

3. López Gay y Mulder (2012) analizan el efecto del tamaño de las generaciones sobre la movilidad metropolitana en el caso de Barcelona. 
Figura 7. Evolución del saldo migratorio neto metropolitano entre centro y periferia por origen (2005-2016)

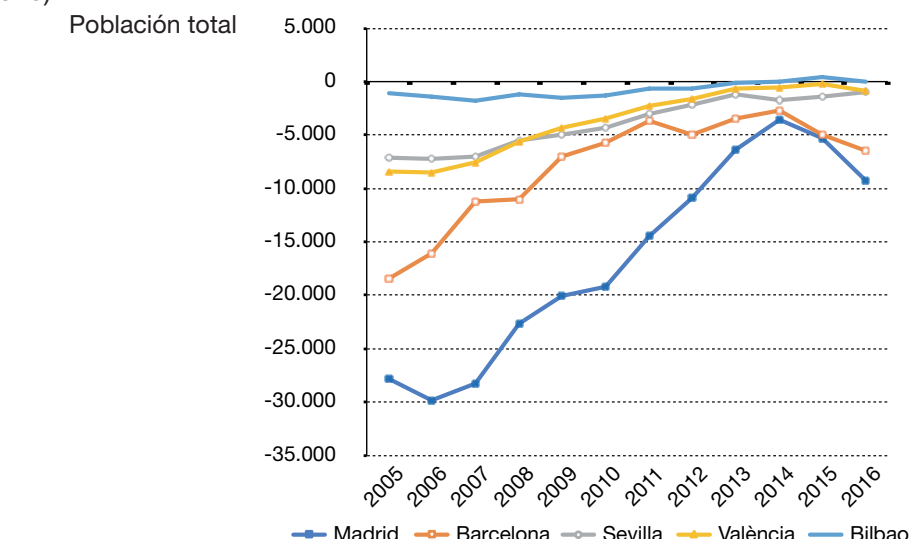

Població autóctona

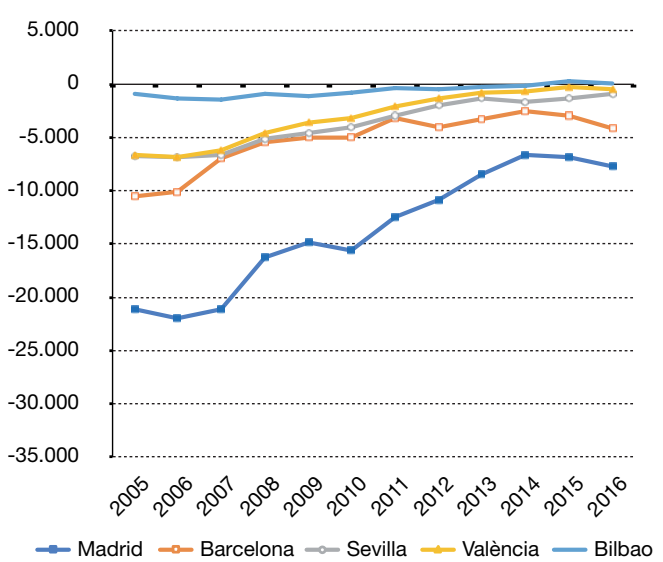

Població inmigrada

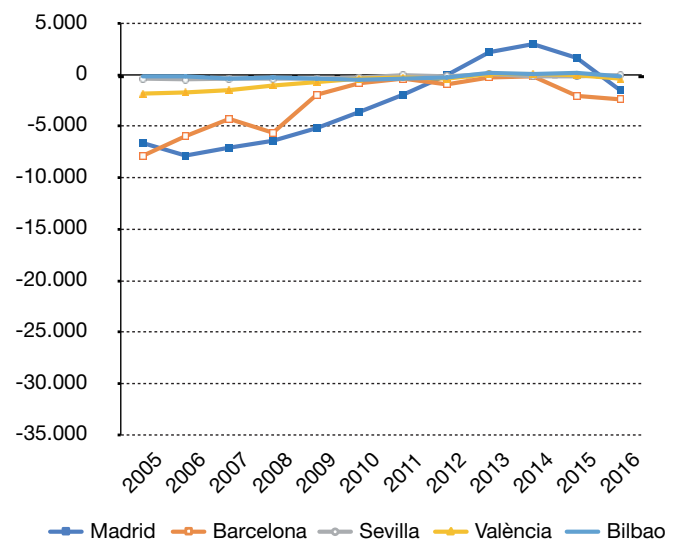

Fuente: elaboración propia. Estadística de variaciones residenciales, 2005-2016, con datos del INE. 
Figura 8. Perfiles por sexo y edad de los saldos migratorios entre el centro y la periferia metropolitana (2005-2016)

Madrid

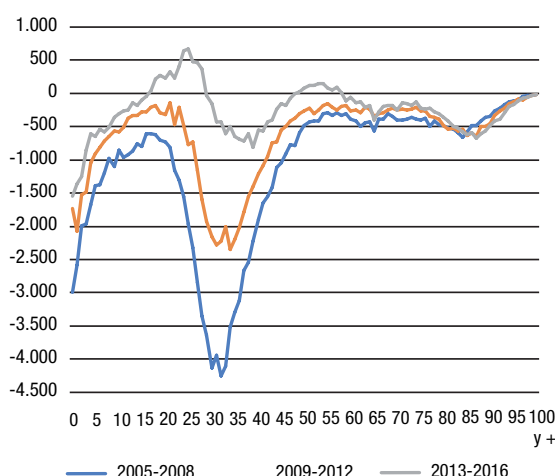

-2005-2008 2009-2012 2013-2016

Valencia

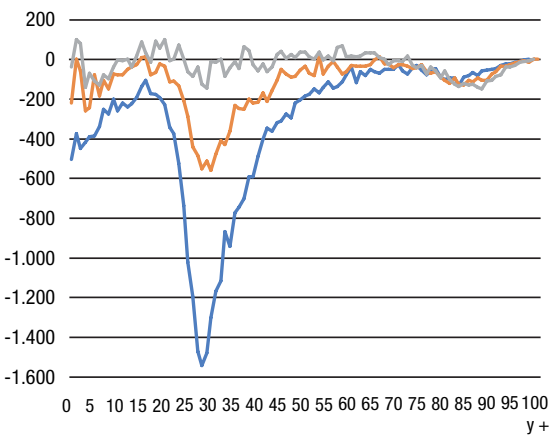

$-2005-2008-2009-2012-2013-2016$

\section{Barcelona}

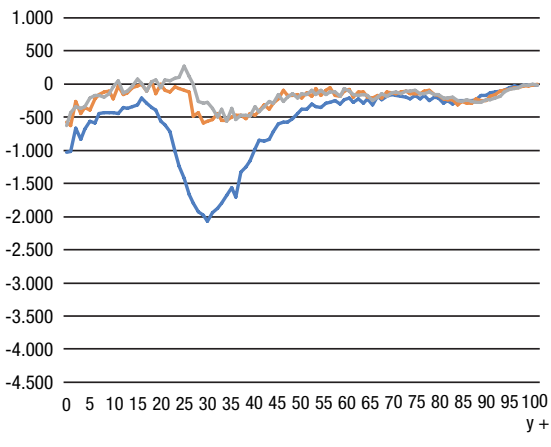

-2005-2008 2009-2012 2013-2016

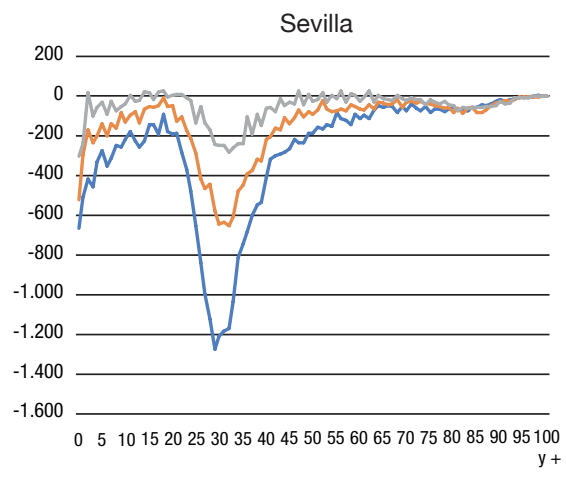

Bilbao

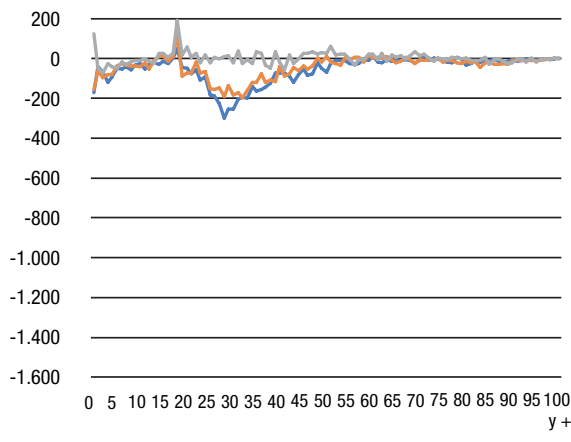

- 2005-2008 2009-2012 2013-2016

Fuente: elaboración propia. Estadística de variaciones residenciales, 2005-2016, con datos del INE. 
bién, en tercer lugar, y en esto coinciden las cinco urbes, la disminución de las salidas provoca un aumento progresivo (y una visibilización progresiva) del saldo migratorio positivo de los más jóvenes, puesto que estas ciudades incorporan población de entre 20 y 25 años de edad. Este proceso no es nuevo, aunque se intensifica recientemente entre jóvenes con elevados niveles de formación (López-Gay, 2018). Finalmente, en contraposición a los cambios descritos, el grupo de mayores de 80 años conoce muy pocas variaciones en el tiempo, puesto que siempre muestra un saldo migratorio metropolitano negativo en estas edades y un impacto sobre el saldo global cada vez más elevado ${ }^{4}$.

\section{La composición de la población por edades}

Estas dinámicas migratorias contrapuestas según la edad y el ciclo vital de los individuos acaban provocando que la composición de centros y periferias metropolitanas se diferencien progresivamente de acuerdo con los años que tiene su población (figura 9). La representación de estas estructuras mediante una pirámide de edades nos permite comparar los resultados de los diferentes procesos demográficos que se han producido a escala metropolitana. De esta forma se observa que la estructura etaria de los centros es siempre más envejecida, y este envejecimiento se incrementa con el paso del tiempo, al comparar 1998 con 2016. Esta situación es especialmente visible en las edades situadas por encima de los ochenta años. Al mismo tiempo, la presencia de menores es siempre inferior en los centros, con un número de efectivos que prácticamente no varía entre las edades por debajo de los veinte años, signo de una fecundidad baja y con pocas variaciones temporales en las ciudades centrales (Kulu y Boyle, 2009), como es el caso de la ciudad de Barcelona (Pujadas et al., 2013). En cambio, las periferias concentran población adulta joven, en su mayoría entre los 35 y los 50 años de edad, y que ha sido la protagonista reciente del proceso de suburbanización. Son, además, las mismas generaciones nacidas con el baby boom de las décadas de 1960 y 1970 en España, a las que se añadieron volúmenes importantes de inmigrantes extranjeros durante los primeros años de siglo XXI.

De igual modo, es interesante comparar las pirámides de los centros con sus periferias respectivas. El mayor contraste entre un centro envejecido y una periferia muy joven se da entre Madrid y sus alrededores suburbanos, con una alta concentración de población joven adulta y una base amplia de población infantil, lo que traduce tanto la importancia de la movilidad residencial como su persistencia hasta años muy recientes. En las restantes áreas urbanas el contraste es menor, debido a unas intensidades más moderadas de la suburbanización residencial, caso de Valencia y Sevilla, o bien a procesos de suburbanización más antiguos que han favorecido una mayor aproximación a lo largo

4. Ver Pujadas et al. (2016) para un análisis específico de la movilidad a escala metropolitana de población en estas edades avanzadas. 
Figura 9. Estructura por edades de la población metropolitana, centros y periferias metropolitanas (1998-2016)

Centro

Madrid
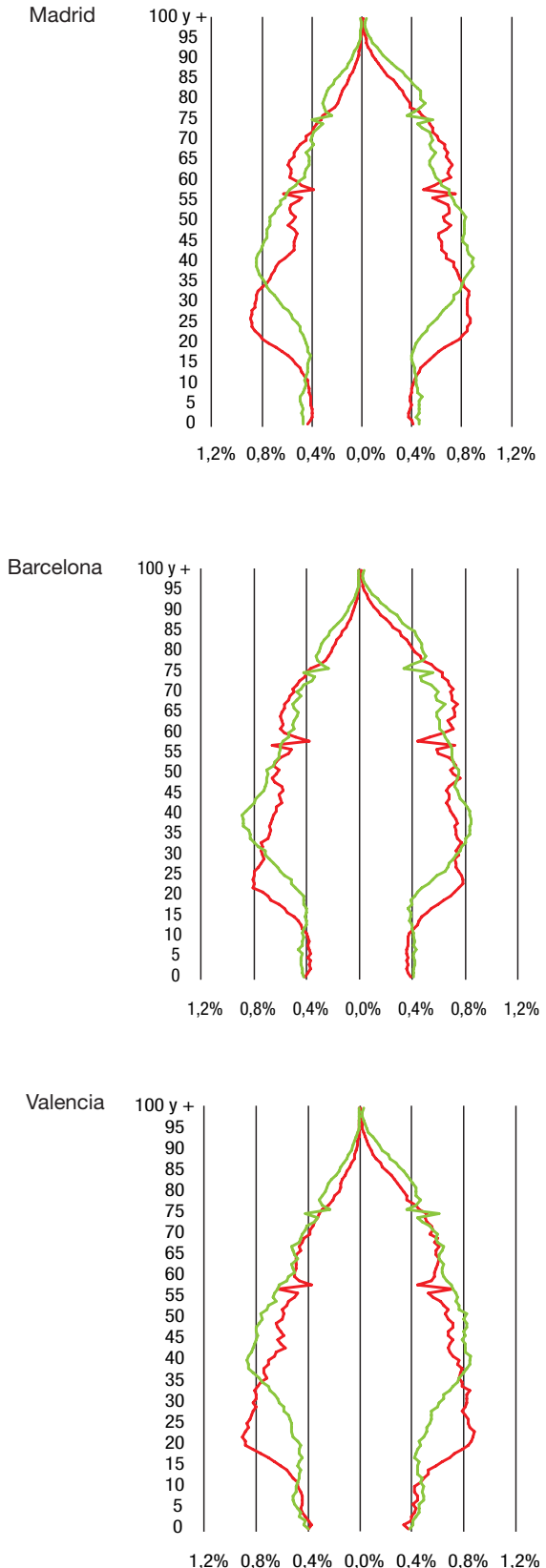

Resto AM
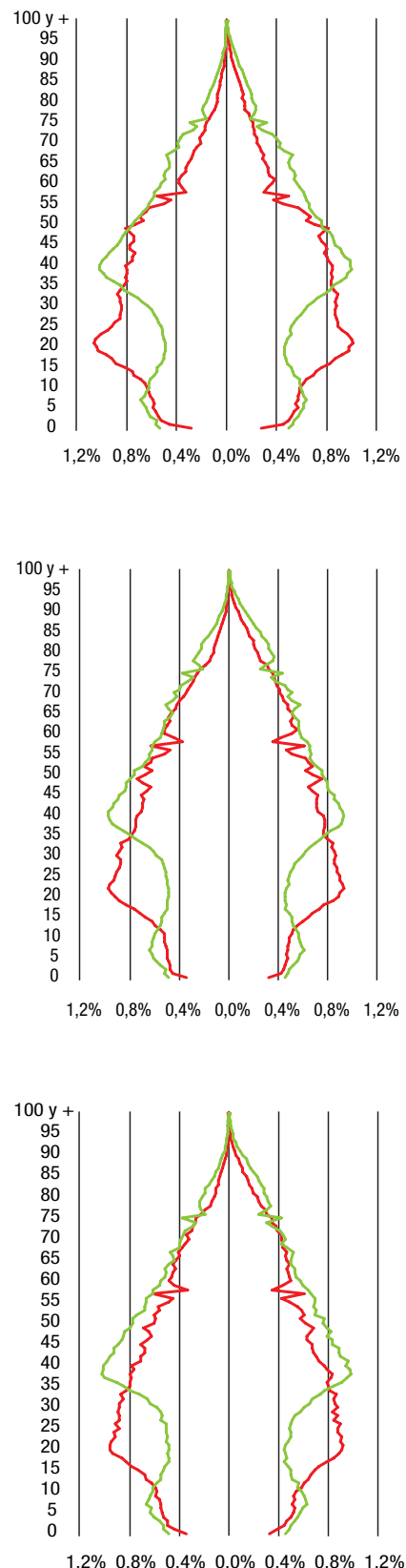
Centro
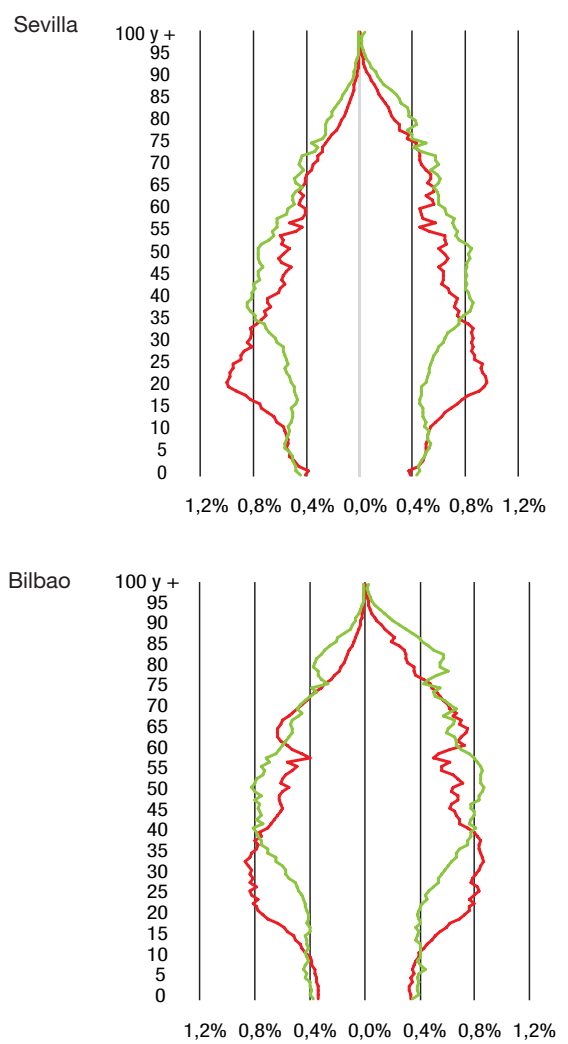

Resto AM
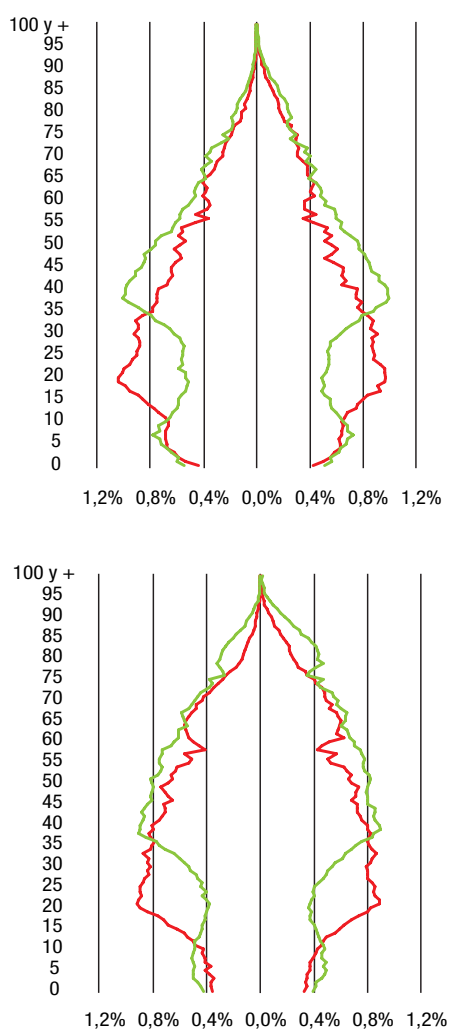

2016

Fuente: elaboración propia. Padrón continuo de población, a 1 de enero de 2016, con datos del INE.

del tiempo entre las estructuras demográficas del centro y la periferia, caso de Barcelona, o bien a una suburbanización de baja intensidad, caso de Bilbao, con apenas diferencias destacadas en las pirámides de la capital y su periferia.

Finalmente, cabe decir que el principal cambio reciente en la estructura por edades se produce entre los jóvenes, en personas que se encuentran por debajo de los 35 años, como reflejo del descenso intenso de la fecundidad desde la década de 1980 en España. La leve recuperación de la natalidad en los años anteriores a la crisis económica (2001-2008) solo se observa en las periferias, mientras que este proceso no puede identificarse en la mayoría de las estructuras de los centros metropolitanos.

Otra forma de observar estas pautas cambiantes es a partir del peso que los grupos etarios de la ciudad central representan sobre las mismas edades en el total metropolitano, ejercicio que se representa en la figura 10 para los años 
1998, 2005 y 2016. Además, se han unido mediante unas rectas los datos de diferentes edades en 1998 ( 1 año, 10 años, 20 años y así sucesivamente) con las equivalentes en 2016, para comprobar la evolución de dichos pesos en el tiempo desde una perspectiva generacional. Para todo ello se han empleado los datos del Padrón continuo de población, donde existe una sobrerrepresentación del grupo de 0 años en las ciudades centrales. Es por esta cuestión que dicha edad no se ha tenido en cuenta en el análisis 5 .

Los resultados admiten diferentes lecturas. Por un lado, la comparación entre las cinco regiones metropolitanas redunda en los distintos niveles de los porcentajes de la población de partida, especialmente en los casos de Barcelona y Bilbao, muy por debajo en todas las edades de los valores del resto de metrópolis. Por el otro, existe un efecto etario muy importante, con un crecimiento de la representación de las personas con más años en la ciudad central, fruto del continuado y progresivo proceso de dispersión residencial que no afectó por igual a las distintas generaciones y que se observa en los cinco casos analizados. En tercer lugar, se destaca la existencia de inflexiones positivas entre los jóvenes, que alcanzan intensidades muy importantes y que deben explicarse tanto por la entrada de migrantes internacionales a estas edades como por una cierta atracción de la ciudad central sobre estos perfiles de edad. En el caso de Madrid esta situación se produce en distintos grupos etarios, dando un carácter cíclico a las dinámicas migratorias metropolitanas. En este punto es significativa la tendencia alcista que se observa en Barcelona, y en menor medida en Madrid, en el grupo que actualmente representa a los jóvenes. La comparación entre los 10 años de 1998 y los 28 de 2016 indican un elevado aumento de este grupo de edad, solo explicable desde el punto de vista de las migraciones, ya sean internas como internacionales (una reducción de la migración centro-periferia y la importancia de la inmigración internacional para los centros urbanos). En Valencia, en cambio, no puede identificarse esta situación, mientras que en Madrid, Bilbao y Sevilla es perceptible, aunque con menor intensidad.

\section{Conclusiones}

La intensidad de la crisis económica del último decenio ha representado un nuevo cambio de etapa en el desarrollo metropolitano reciente en España, tal como lo demuestran los datos de las cinco mayores regiones metropolitanas del país. La creciente relación observada entre estas etapas y los flujos migratorios internacionales provoca una mayor dependencia de la coyuntura económica del momento. De esta forma se produce una rápida finalización de la etapa de intenso crecimiento demográfico relacionada con el boom migratorio internacional, lo que da lugar a una nueva situación caracterizada por el estancamiento demográfico, donde la reducción de la movilidad residencial, así como el peso

5. No se consideran los 0 años de edad por los posibles problemas de registro en el padrón continuo de este grupo, que podrían dificultar la comparación diacrónica y la geográfica. La sobrerrepresentación de la ciudad central en los datos de 1998 es un ejemplo de ello. 
Figura 10. Distribución por edades del peso demográfico (\%) de la población de la ciudad central sobre el total de la población metropolitana. 1998, 2005 y 2016

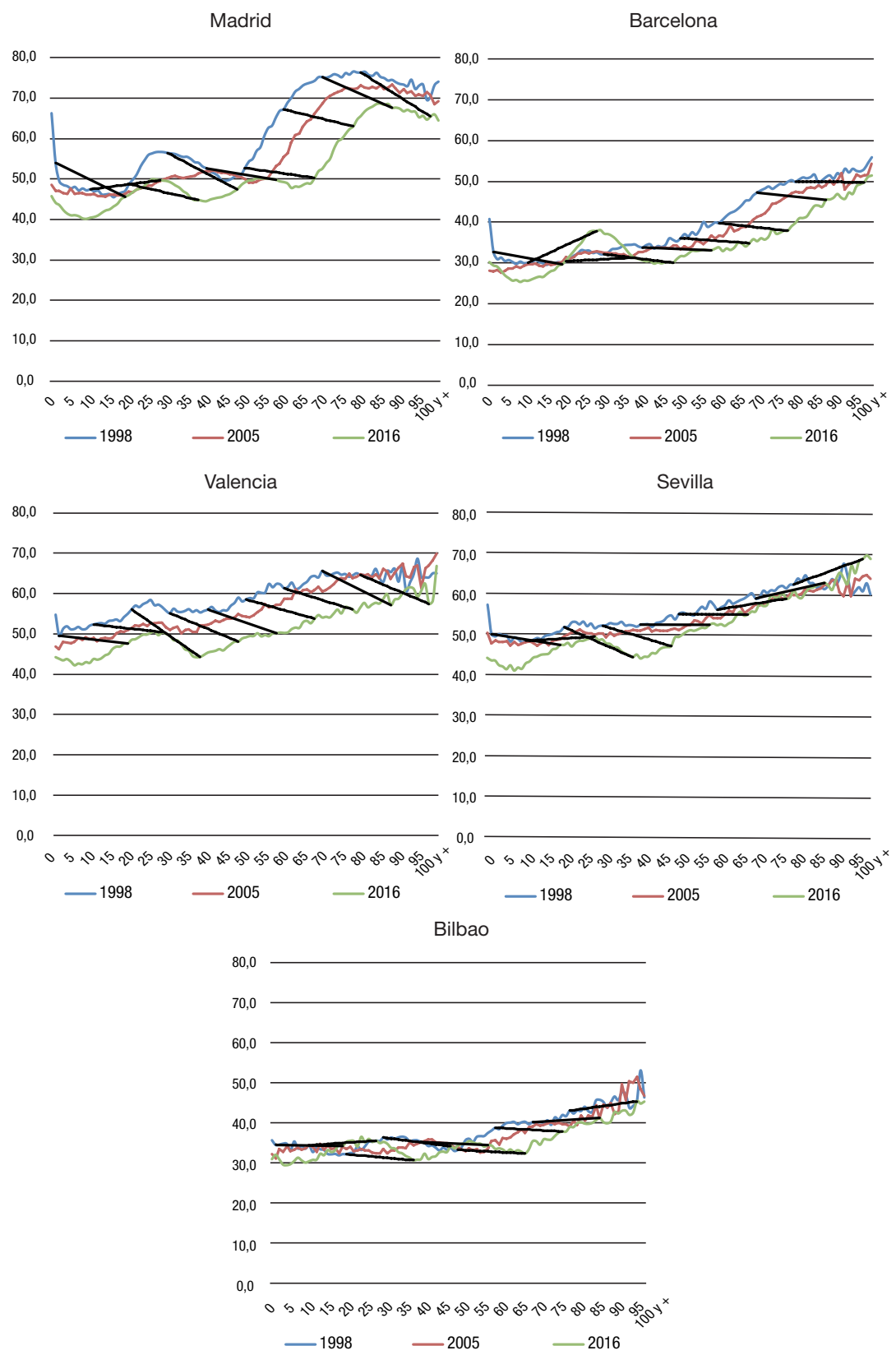

Fuente: Padrón continuo de población, 1998, 2005 y 2016, con datos del INE. 
de la estructura demográfica y de la dinámica natural de los municipios metropolitanos pasan a ser importantes.

Los resultados indican que desde el año 1981 se observan muchas similitudes en el desarrollo demográfico de las áreas seleccionadas, especialmente entre Barcelona y Madrid. También se apunta a un posible final de la transición de la movilidad residencial, ya que se documenta una gran reducción de la dispersión residencial (y con ello de su capacidad transformadora del territorio), así como una cierta recuperación del peso de la población joven en los centros urbanos. Por otra parte, la estructura demográfica juega un rol determinante en la evolución futura en cuando puede actuar conteniendo la dispersión residencial de los jóvenes, pero, al mismo tiempo, reduciendo aún más los ya por sí mismos bajos niveles de natalidad. Esta dinámica demográfica de baja intensidad nos lleva a pensar en una menor variabilidad de los cambios demográficos futuros $\mathrm{y}$, en consecuencia, en una menor diferenciación sociodemográfica del territorio en comparación con lo que ha sucedido durante estos últimos años, caracterizados por cambios de elevada intensidad.

A pesar de estas dinámicas, siguen apareciendo varios interrogantes acerca de la evolución urbana futura. Por un lado, las periferias metropolitanas siguen y seguirán siendo atractivas para buena parte de la población, con unos flujos de salida que no llegan a desaparecer, incluso se insinúan nuevos crecimientos en su volumen debido al boom inmobiliario que vuelven a padecer las ciudades centrales. A diferencia de etapas anteriores, la coyuntura demográfica tiene menor peso, y en cambio aparecen nuevos fenómenos como la creciente turistificación y el incremento del precio de los arrendamientos urbanos. Estos últimos contrarrestan el menor efecto estructura, cuando la reducción del tamaño de las generaciones más la desaparición de hogares en la cúspide de la pirámide parecían insinuar la posibilidad de la aparición de movimientos de recentralización (López-Gay, 2014). Del otro lado, no se debe descartar la posibilidad de la aparición de nuevos flujos migratorios internacionales de cierta intensidad, lo que añade un elevado grado de incertidumbre sobre la evolución futura.

\section{Referencias bibliográficas}

Alabart, A. (2007). «Mobilitat residencial, solidaritat familiar i ciutadania a les regions metropolitanes». Revista Catalana de Sociología, 22, 12-13.

Arango, J. (2007). «Les primeres migracions del segle xx a Catalunya». En: Nadala 2007. Immigració: Les onades migratòries a la Catalunya contemporània. Barcelona: Fundació Lluís Carulla, 18-33.

BAyONA, J. y GiL, F. (2012). «Suburbanisation and international immigration: The case of The Barcelona Metropolitan Region (1998-2009)». Tijdschrift voor Economische en Sociale Geografie, 103 (3), 312-329. <https://doi.org/10.1111/j.1467-9663.2011.00687.x>

Bayona, J.; Gil, F.; Pujadas, I. y Rubiales, M. (2018). «New Spatial Mobility Patterns in Large Spanish Cities: From the Economic Boom to the Great Recession». Applied Spatial Analysis and Policy, 11 (2), 287-312. $<$ https://doi.org/10.1007/s12061-017-9222-x> 
Bayona, J. y Pujadas, I. (2014). «Movilidad residencial y redistribución de la población metropolitana: Los casos de Madrid y Barcelona». EURE: Revista Latinoamericana de Estudios Urbanos y Regionales, 40 (119), 261-287. <https://doi.org/10.4067/s0250-71612014000100012>

Bayona, J. y Recaño, J. (2016). «La movilidad intraurbana en Barcelona y Madrid: Un estudio comparativo». En: Domínguez Mujica, J. y Díaz Hernández, R. (coord.). Población y territorio en la encrucijada de las ciencias sociales: Actas del XV Congreso de la Población Española (pp. 335-350). Universidad de Las Palmas de Gran Canaria.

Berg, L. van den; Drewett, R.; Klaasen, L.H.; Rossi, A. y Vijverberg, C. (1982). Urban Europe: A Study of Growth and Decline. Oxford: Pergamon.

Burriel, E.L. (2008). «La década prodigiosa del urbanismo español (1997-2006)». Scripta Nova: Revista Electrónica de Geografía y Ciencias Sociales, XII, 270 (64).

Champion, T. (2001). «Urbanization, Suburbanization, Counterurbanization and Reurbanization». En: PAdison, R. (ed.). Handbook of Urban Studies. Londres: SAGE.

Cocola, A. (2018). Struggling with the leisure class: Tourism, gentrification and displacement. Cardiff University. PhD Thesis.

Cos, O. de (2007). "La dinámica metropolitana en España: Análisis estadístico y cartográfico de los municipios a partir de la población y de la vivienda». Geographicalia, 51, 59-80.

Cos, O. de y Reques, P. (2005). "Los cambios en los patrones territoriales de la población española (1900-2001)». Papeles de Economía Española, 104, 167-192.

Domingo, A. y Blanes, A. (2015). «Inmigración y emigración en España: Estado de la cuestión y perspectivas de futuro». En: Arango, J. et al. (eds.). Anuario de la Inmigración en España 2014. Barcelona: CIDOB, 94-122.

Donat, C. (2018). "La gentrificació i el problema de l'habitatge a Barcelona». Papers: Regió Metropolitana de Barcelona, 60, 114-129.

FERIA, J.M. (2010). «La movilidad residencial y los procesos de urbanización metropolitanos en España». En: Feria, J.M. y Albertos, J.M. (coord.). La ciudad metropolitana en España: Procesos urbanos en los inicios del siglo XXI. Cizur Menor (Navarra): Thomson Reuters, 23-48.

Franch, X.; Martí-Henneberg, J. y Puig, J. (2013). «Un análisis espacial de las pautas de crecimiento y concentración de la población a partir de series homogéneas: España (1877-2001)». Investigaciones Regionales, 25, 43-65.

Fundación BBVA e IVIE (Instituto Valenciano de Investigaciones EconóMICAS) (2015). Cambios en la estructura y localización de la población: Series homogéneas (1900-2011). Noviembre de 2015. Recuperado de <http://www.fbbva.es/ TLFU/tlfu/esp/areas/econosoc/bbdd/serieshomg.jsp >.

Ganau, J. y Vilagrasa, J. (2003). «Ciudades medias en España: Posición en la red urbana y procesos urbanos recientes». En: CAPEL, H. (coord.). Ciudades, arquitectura y espacio urbano. Almería: Cajamar, 36-73. Mediterráneo Económico. Colección de Estudios Socioeconómicos, 3.

García Coll, A. y López Villanueva, C. (2017). «El fenómeno de la dispersión territorial en la Región Metropolitana de Barcelona: Espacios, actores y tendencias». Papers: Revista de Sociologia, 102 (4), 727-760. <https://doi.org/10.5565/rev/papers.2418>

García Coll, A. y Pujadas, I. (1997). "Les migracions interiors a Espanya a finals de segle xx». Treballs de la Societat Catalana de Geografia, XII (44), 231-249. 
García Docampo, M. y Otero, R. (2012). «Transición territorial: Modelo teórico y contraste con el caso español». Reis, 139 (julio-septiembre), 133-162.

García-López, M.A. (2008). «Quince años de suburbanización en la Barcelona metropolitana: ¿¿Se está dispersando la población?». Investigaciones Económicas, 32 (1), 53-86.

García Palomares, J.C. y Gutiérrez Puebla, J. (2007). «La ciudad dispersa: Cambios recientes en los espacios residenciales de la Comunidad de Madrid». Anales de Geografía de la Universidad Complutense de Madrid, 27 (1), 45-67.

Gil-Alonso, F.; Bayona, J. y Pujadas, I. (2016). «From boom to crash: Spanish urban areas in a decade of changes (2001-2011)». European Urban and Regional Studies, 23 (2), 198-216. <https://doi.org/10.1177/0969776413498762>

Goerlich, F.J. y Mas, M. (2008). "Algunas pautas de localización de la población española a lo largo del siglo xx». Investigaciones Regionales, 12, 5-24.

Kulu, H. y Boyle, P. (2009). "High Fertility in City Suburbs: Compositional or Contextual Effects?». European Journal of Population, 25, 157-174.

López-Gay, A. (2014). "Population growth and re-urbanization in Spanish inner cities: The role of internal migration and residential mobility». Revue Quetelet, 2 (1), 67-92.

- (2017). «Hacia un patrón territorial complejo de la movilidad residencial: El caso de la Región Metropolitana de Barcelona». Papers: Revista de Sociologia, 104 (4), 793-823.

<https://doi.org/10.5565/rev/papers.2420>

- (2018). "Cambio en la composición social y gentrificación en Barcelona: Una mirada a través de los flujos migratorios y residenciales». Papers: Regió Metropolitana de Barcelona, 60, 80-93.

López-Gay, A. y Mulder, C. (2012). «Implicaciones del tamaño de las generaciones en la movilidad residencial: El caso de Barcelona». En: Reques, P. y Cos, O. de (eds.). La población en clave territorial: Procesos, estructuras y perspectivas de análisis. Actas XIII Congreso de la Población Española. Madrid: Ministerio de Economía y Competitividad.

López-Villanueva, C. y Pujadas, I. (2005). «Hogares y cambios residenciales: La diferenciación territorial de los hogares en la Región Metropolitana de Barcelona». Cuadernos Geográficos de la Universidad de Granada, 36, 409-436.

- (2015). «Transformaciones espaciales y demográficas en las regiones metropolitanas de Madrid y Barcelona». En: Domínguez, M. y López, C. (coord.). Barcelona y Madrid: Procesos urbanos y dinámicas sociales. Madrid. Síntesis, 71-105.

Miralles, C. (2011). "Dinámicas metropolitanas y tiempos de la movilidad: La Región Metropolitana de Barcelona, como ejemplo». Anales de Geografía de la Universidad Complutense de Madrid, 31 (1), 125-145.

Módenes, J.A. (1998). Flujos espaciales e itinerarios biográficos: La movilidad residencial en el área de Barcelona. Tesis doctoral. Departamento de Geografía. UAB.

- (2019). "L'insostenible augment de la inseguretat residencial a Espanya». Perspectives Demogràfiques, 13.

NeL.LO, O. (2004). «¿Cambio de siglo, cambio de ciclo?: Las grandes ciudades españolas en el umbral del siglo xxI». Ciudad y Territorio: Estudios Territoriales, 141-142, 523-542.

- (2007). "Spain: Changing Century, Changing Cycle?: Large Spanish Cities on the Threshold of the Twenty-first Century». En: Berg, Leo van den; Braun, 
Erik y Meer, J. van der. National Policy Responses to Urban Challenges in Europe. Farnham, Reino Unido: Ashgate, 333-360.

- (2010). «Les dinàmiques territorials a la Regió Metropolitana de Barcelona (19862006): Hipòtesis interpretatives». Papers: Regió Metropolitana de Barcelona, 52, 16-27.

Pozo, E. y García-Palomares, J.C. (2009). «Inmigración y cambio demográfico en la región metropolitana madrileña entre 1996 y 2006». Anales de Geografía de la Universidad Complutense, 29 (1), 111-138.

Pozo, E. y Rodríguez Moya, J.M. (2018). «Impacto de la crisis en los movimientos migratorios en la comunidad de Madrid (2007-2013)». Boletín de la Asociación de Geógrafos Españoles, 77, 229-255. <https://doi.org/10.21138/bage.2540>

Pujadas, I. (2009). «Movilidad residencial y expansión urbana en la Región Metropolitana de Barcelona, 1982-2005». Scripta Nova: Revista Electrónica de Geografía y Ciencias Sociales, XIII (290).

Pujadas, I. y Bayona, J. (2017). «Dinámicas demográficas recientes en las áreas urbanas españolas en un contexto de crisis». En: Sempere, J.D. y Cutillas, E. (eds.). La población en España: Cuarenta años de cambio (1975-2015). Alicante: Departament de Geografia Humana. Publicacions de la Universitat d'Alacant, 133-156.

Pujadas, I.; Bayona, J.; Gil, F. y López-Villanueva, C. (2013). «Pautas territoriales de la fecundidad en la Región Metropolitana de Barcelona (1986-2010)». Estudios Geográficos, LXXIV (275), 585-609. <https://doi.org/10.3989/estgeogr.201321>

Pujadas, I.; Bayona, J. y Rubiales, M. (2016). «Movilidad residencial en edades avanzadas en España: Una perspectiva metropolitana». Finisterra: Revista Portuguesa de Geografia, LI (102), 121-142. <https://doi.org/10.18055/finis4250>

Reques, P. (2017). «La transición territorial. Cambios en las estructuras demoespaciales en España (1900-2011): Un análisis de base municipal». En: SEMPERE, J.D. y Cutillas, E. (eds.). La población en España: Cuarenta años de cambio (19752015). Alicante: Departament de Geografia Humana. Publicacions de la Universitat d'Alacant, 67-132.

RÉrat, P. (2012). "The New Demographic Growth of Cities: The Case of Reurbanisation in Switzerland». Urban Studies, 49 (5), 1107-1125.

Salom, J. y Albertos, J.M. (2014). «Delimitación y caracterización de los nuevos espacios urbanos valencianos». Boletín de la Asociación de Geógrafos Españoles, 64, 127-149.

Susino, J. y Duque, R. (2013). "Veinte años de suburbanización en España (19812001): El perfil de sus protagonistas». Documents d'Anàlisi Geogràfica, 59 (2), 265-290.

<https://doi.org/10.5565/rev/dag.31> 
